\title{
Estudo de usabilidade das máquinas de costura industrial com alunos de graduação em moda
}

Usability study on industrial sewing machines with undergraduate fashion students

Raquel Pizzolato Cunha de Oliveira

Universidade do Estado de Santa Catarina

raquel.pizzolato@gmail.com

Alexandra Marcela Porto

Universidade do Estado de Santa Catarina

alexandramsporto@gmail.com

$\mathbf{X}$

\section{Claudia Crepaldi}

Universidade do Estado de Santa Catarina

cla0608@gmail.com

M

Marcelo Gitirana Gomes Ferreira

Universidade Federal de Santa Catarina

marcelo.gitirana@gmail.com

\section{PROJËTICA}

\section{COMO CITAR ESTE ARTIGO:}

OLIVEIRA, R. P. C.; PORTO, A. M.; CREPALDI, C.; FERREIRA, M. G. G. Estudo de usabilidade das máquinas de costura industrial com alunos de graduação em moda. Projética, Londrina, v. 11, n. 1, p 81-107, 2020.

DOI: 10.5433/2236-2207.2020v11n1p81

Submissão: 22-08-2018

Aceite: $26-07-2019$

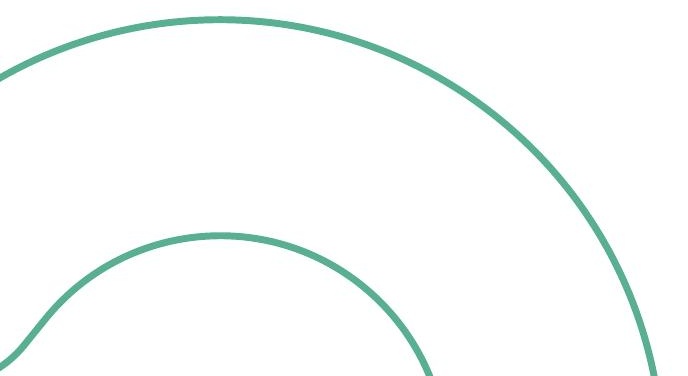


Projética, Londrina, v.11, n.1, p. 81-107, abril 2020

RESUMO: Este artigo teve por objetivo avaliar a usabilidade da máquina de costura reta industrial com alunos de um curso de graduação em moda, para verificar o quanto a usabilidade pode influenciar sobre o interesse destes alunos na prática da costura. Para tal, através de questionários e testes de usabilidade, pretendeuse identificar obstáculos no uso das máquinas de costura por parte dos alunos e analisar como os níveis de familiarização com as máquinas industriais influenciam na experiência do usuário. Foram avaliados fatores como expectativa, experiência e sentimentos do usuário. Como resultado percebeu-se que fatores subjetivos como a percepção de agradabilidade, tomadas antes e depois da execução das tarefas se mostraram distintas, uma vez que o experimento permitiu ao participante desmistificar possíveis impressões e noções previamente estabelecidas. Contudo os resultados e sentimentos mais negativos foram atribuídos aos indivíduos leigos demonstrando que os níveis de familiarização com as máquinas industriais influenciam na experiência do usuário.

Palavras-chave: Teste de usabilidade. Máquinas de costura. Estudantes de moda. Experiência do usuário.

ABSTRACT: This study aims to evaluate aspects related to the usability of the industrial sewing machine with students of a graduation course in fashion design, in order to verify how usability can influence the interest of students in the practice of sewing. To do so, we applied questionnaires and usability tests to identify obstacles in the use of the sewing machines by the students and to analyze how the levels of familiarization with the industrial machines influence the user experience. Factors such as expectation, experience and the user's feelings were evaluated. As a result, it was noticed that subjective factors such as the perception of pleasantness taken before and after the execution of the tasks was different, once the tests allowed participants to revisit their first impressions. However, the most negative results and feelings were collected from untrained students, demonstrating that levels of familiarity with industrial machines in fact influence the user experience.

Keywords: Usability tests. Sewing machines. Fashion design students. User experience. 


\section{INTRODUÇÃO}

Conhecer a prática do corte e da costura, bem como promover a habilidade do uso efetivo das máquinas de costura é um dos requisitos obrigatórios para a formação de alunos de um curso superior de moda. Entre os estudantes que visam ocupar funções profissionais relacionadas ao processo produtivo do vestuário, esse conhecimento é fundamental para execução de etapas como pilotagem e prototipagem, e para a comunicação de maneira eficiente e eficaz dentro das empresas de confecção nas quais os estudantes um dia poderão atuar.

Entretanto, observa-se uma crescente falta de interesse e dedicação destes alunos nas disciplinas que envolvem a prática da confecção. Pressupõe-se que essa falta de interesse esteja ligada, entre outros fatores, a problemas de usabilidade inerentes aos equipamentos (máquinas de costura) utilizados nos ateliês de costura.

Desta forma, este artigo tem por objetivo avaliar a usabilidade de uma máquina de costura industrial (costura reta) com alunos do curso de moda da Universidade do Estado de Santa Catarina (UDESC), de tal forma a verificar o quanto a usabilidade pode influenciar sobre o interesse destes alunos na prática da costura. Para tal, através de testes de usabilidade, pretendeu-se identificar obstáculos no uso das máquinas de costura por parte dos alunos e analisar como os níveis de familiarização com as máquinas industriais influenciam na experiência do usuário.

\section{MATERIAIS E MÉTODOS}

Os autores realizaram um teste de usabilidade com o objetivo de identificar se existem aspectos ligados à usabilidade de máquinas de costura industrial que 
Projética, Londrina, v.11, n.1, p. 81-107, abril 2020

influenciam no interesse e interação de uma amostra de alunos do curso de Bacharelado em Moda da UDESC. Para isso, o teste foi aplicado de forma composta, estruturado da seguinte maneira:

a) Triagem dos participantes aptos a realização dos testes;

b) Resposta ao questionário "Pretensão na área da moda"

c) Resposta ao questionário "Percepção e expectativa em relação a dificuldade das tarefas";

d) Aplicação do "Conjunto de Tarefas 1" e "Conjunto de Tarefas 2";

e) Resposta ao questionário pós-tarefa;

f) Realização de debriefing ou sessão de revisão da experiência.

\subsection{Objeto de Teste: a Máquina de Costura}

De modo geral, a estrutura de uma máquina de costura se divide nas seguintes partes: braço, corpo, cabeça e base. As partes do braço, corpo e cabeça são as partes que contêm os mecanismos exteriores. A base, por sua vez, é a parte a qual o tecido é colocado durante a operação, podendo variar a direção de deslocamento deste em relação à base e a estrutura física da máquina (ARAÚjO, 1996). Essencialmente, as máquinas de costura são classificadas a partir do tipo de base (base em braço, base cilíndrica, base plana) do tipo de ponto (overloque, reta, etc.) ou de sua função (botoneira, galoneira, etc.) podendo ser domésticas ou industriais.

A máquina de costura selecionada para o teste foi a Reta Industrial Silver Star, por se tratar de um modelo disponível no ateliê de moda da UDESC, onde os testes foram realizados, e por ser o equipamento comumente utilizado pelos alunos investigados neste estudo. 
Figura 1 - Modelo da máquina de costura utilizada nos testes

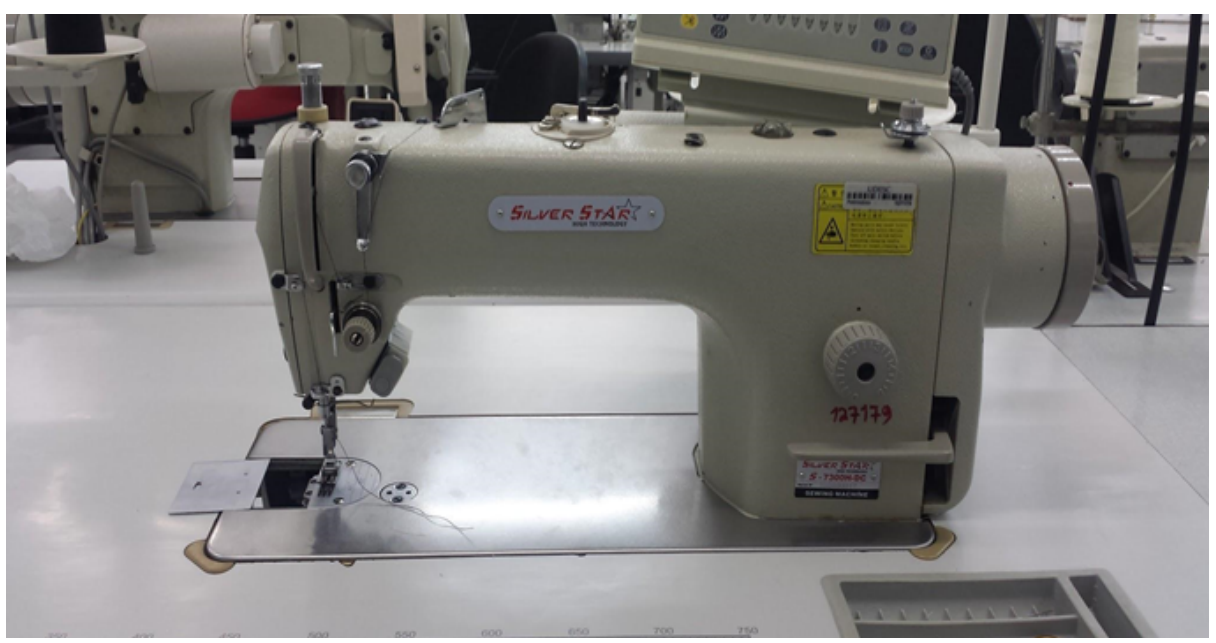

Fonte: Os autores (2017).

\subsection{Os Participantes}

Com a finalidade de angariar participantes voluntários para o experimento proposto, os autores buscaram juntamente ao departamento de Moda da UDESC o apoio na divulgação desta pesquisa, bem como do questionário de triagem realizado online, entre alunos e ex-alunos do curso de moda da UDESC. Também foi através deste departamento que se obteve as autorizações para utilizar o espaço do ateliê de costura desta instituição.

A fim de atender ao escopo do estudo, os participantes foram selecionados conforme os seguintes critérios: alunos ou ex-alunos do curso de Moda da UDESC, maiores de 18 anos, com diferentes níveis de experiência prévia com o uso de máquinas de costura, excluindo os que tivessem experiência de manuseio com as máquinas industriais. Foram categorizados de acordo com seus níveis de familiaridade acerca do conhecimento sobre máquinas de costura industrial. 
Projética, Londrina, v.11, n.1, p. 81-107, abril 2020

Foram considerados leigos os participantes que não tinham tido nenhum contato com qualquer tipo de máquina de costura; iniciantes os que tinham familiaridade com alguma máquina de costura, mas nunca tinham tido contato com máquinas de costura industriais; e aprendizes aqueles que sabiam costurar, porém não dominavam o manuseio básico para o funcionamento da máquina industrial.

Foi aplicado um questionário de triagem online, entre alunos e ex-alunos do curso de Moda da UDESC, no período de 31/05/2017 e 07/06/2017. A partir dele, foram obtidas 17 respostas, sendo que apenas 14 alunos preencheram os requisitos de inclusão e foram convocados a participar do estudo. Uma das voluntárias não pode participar devido à impossibilidade de comparecer ao local na semana dos testes. Assim, o teste foi agendado com 13 voluntários, entre os dias 20 e 23/06/2017, no ateliê de costura do curso de Moda da Universidade do Estado de Santa Catarina. Um dos voluntários não compareceu no horário do teste, restando 12 indivíduos participantes. Os testes foram realizados individualmente, ou seja, com um voluntário por vez, sem que os demais alunos pudessem ter acesso ao ambiente de realização dos testes anteriores, no intuito de eliminar a possibilidade de haver aprendizado entre as etapas. Um teste piloto foi feito para medição do tempo e validação das tarefas, antes da realização com os voluntários. Neste teste foi possível observar se as tarefas propostas estavam adequadas ao objetivo da pesquisa.

\subsection{Coleta de Dados}

Para coletar dados pertinentes à problemática do estudo, foi definida a aplicação de questionários e tarefas a fim de contabilizar e entender melhor alguns fatores influenciadores. Os participantes foram identificados através de números de perfis estabelecidos pelos autores, categorizados em leigos, iniciantes e aprendizes. Esses responderam a um questionário (Quadro 1) sobre sua pretensão na área de moda. 
Após a aplicação deste questionário, ainda antes do início das ações de manuseio com a máquina de costura, foi aplicado um questionário voltado à percepção e expectativa em relação à dificuldade das tarefas por parte dos participantes; esse questionário foi estruturado aos moldes da escala Likert, onde os participantes atribuíram notas de 1 (discordo totalmente) a 5 (concordo totalmente) para sentenças relativas à opinião e impressão dos participantes sobre a máquina de costura industrial. As sentenças incluíram perguntas que consideram o grau de subjetividade presente nesta atividade, levando em consideração aspectos como medo de se machucar ou de errar a costura e à agradabilidade e percepção de qualidade que os participantes consideram existentes neste tipo de máquina.

Na sequência, foram propostos dois conjuntos de atividades, que identificados como Conjunto de Tarefas 1 e Conjunto de Tarefas 2, são melhor explicados nos subitens seguintes. Para ambas as tarefas não foram fornecidos manual de instrução, embora cada participante tenha recebido orientações básicas do funcionamento dos principais comandos necessários para a execução das tarefas. Tal decisão se deu na intenção de observar justamente o quão intuitivo o uso da máquina de costura industrial pode ser e, ao mesmo tempo, buscando não influenciar no tempo de execução das tarefas com consultas prolongadas ao manual.

Os participantes foram instruídos - durante toda a execução das tarefas - a expressar verbalmente suas dificuldades e dúvidas, sem que isso ocasionasse qualquer intervenção por parte do moderador. E, após a realização dos conjuntos de tarefas 1 e 2, foi solicitado ao participante que respondesse a um questionário pós-tarefa, contendo as mesmas perguntas feitas antes da realização da tarefa, baseado no método da medida de expectativa de Albert e Dixon (2003 apud TULLIS; ALBERT, 2008), para comparação de quão fácil ou difícil os participantes esperavam que fosse a tarefa e quão fácil ou difícil de fato foi. Segundo esses autores, "os usuários esperam que algumas tarefas sejam mais fáceis do que outras". Essa classificação pós-tarefa recebe o nome de classificação de experiência. 
Quadro 1 - Ficha de Identificação do participante

\begin{tabular}{|c|c|}
\hline \multicolumn{2}{|c|}{ Número de identificação: } \\
\hline $\begin{array}{l}\text { Nível do } \\
\text { participante: }\end{array}$ & ( ) Leigo ( ) Iniciante ( ) Aprendiz \\
\hline \multirow{8}{*}{$\begin{array}{l}\text { Qual a sua } \\
\text { pretensão em } \\
\text { relação à área de } \\
\text { atuação dentro do } \\
\text { design de moda? }\end{array}$} & $\begin{array}{l}\text { ( ) Consultoria Trabalhar como personal stylist, ajudando os clientes a } \\
\text { combinar roupas, cores e estilos. }\end{array}$ \\
\hline & $\begin{array}{l}\text { ( ) Coordenação Gerenciar a compra de coleções de roupas para lojas } \\
\text { e magazines. Coordenar as equipes de estilos, tanto em indústrias e } \\
\text { confecções como em magazines, e orientá-las para as tendências da moda. }\end{array}$ \\
\hline & $\begin{array}{l}\text { ( ) Design/Estilismo Criar roupas (estilismo), joias, bijuterias, calçados e } \\
\text { bolsas (design de acessórios) ou desenhar estampas e padrões e elaborar } \\
\text { novos tecidos para tecelagens (design têxtil). }\end{array}$ \\
\hline & $\begin{array}{l}\text { ( ) Fotografia Acompanhar a produção de fotos de moda para revistas, } \\
\text { catálogos, exposições e anúncios. }\end{array}$ \\
\hline & $\begin{array}{l}\text { ( ) Gerenciamento Desenvolver produtos e supervisionar a compra de } \\
\text { materiais para sua produção e comercialização. }\end{array}$ \\
\hline & $\begin{array}{l}\text { ( ) Modelagem Transpor para moldes os desenhos dos estilistas, } \\
\text { desenvolvendo modelos-piloto para orientar a produção. }\end{array}$ \\
\hline & $\begin{array}{l}\text { ( ) Negócios Atuar como gestor na cadeia de produção, distribuição, } \\
\text { divulgação e comercialização da moda e desenvolver estratégias de } \\
\text { negócios e marketing. }\end{array}$ \\
\hline & $\begin{array}{l}\text { ( ) Produção Fazer desfiles, catálogos, editoriais de revistas e organizar } \\
\text { campanhas publicitárias. }\end{array}$ \\
\hline
\end{tabular}

Fonte: Os autores (2017).

Por fim, foi realizado um debriefing ou sessão de revisão, onde cada participante foi convidado a expressar suas opiniões sobre as tarefas executadas e as impressões causadas pela experiência. O objetivo dessa etapa foi explorar e revisar as ações dos participantes durante o desempenho dos conjuntos de tarefas do teste e descobrir problemas não identificados pela análise dos dados obtidos pelos questionários ou pelas tarefas práticas.

\subsection{Conjunto de Tarefas 1}

O primeiro conjunto de tarefas consistiu na preparação da máquina para funcionamento. As ações relacionadas à parte inferior da máquina se baseavam 
na inserção de uma bobina previamente preenchida com linha na caixa, encaixe da caixa no estojo, conforme ilustrado na figura 2.

Figura 2 - Tarefas de passagem de linha na parte inferior da máquina. Em sentido horário: par de bobinas, inserção e passagem corretas da bobina na caixa, com detalhe da passagem da linha pelo lingote da caixa, encaixe da caixa com o dente em posição vertical no rebaixo do estojo, encaixe correto da caixa no estojo da máquina

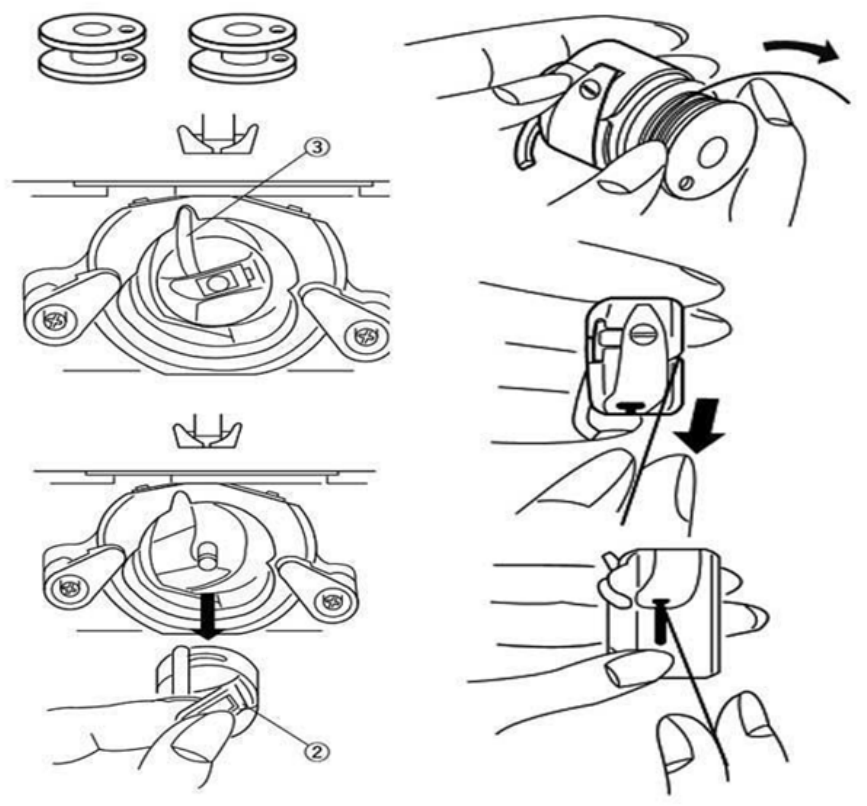

Fonte: Adaptado do Manual... (2008, p. 16).

As ações relacionadas à parte superior da máquina se baseavam em passar a linha nos espaços destinados à passagem de linha e, por fim, passar a linha no buraco da agulha conforme ilustrado na figura 3.

A máquina de costura industrial foi utilizada com regulagem apropriada para tecidos planos e leves, bem como agulha em numeração própria para a costura desse tipo de tecido, sem linhas passadas, na parte superior e inferior. 


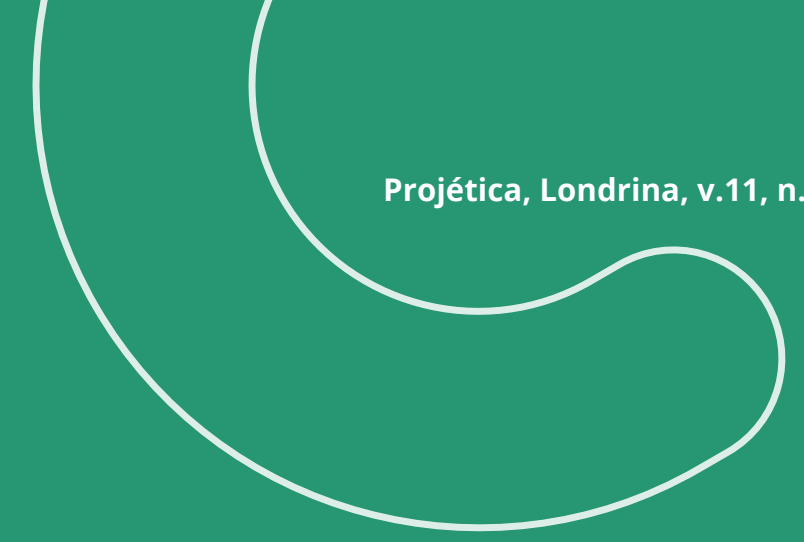

Entretanto, observa-se uma crescente falta de interesse e dedicação destes alunos nas disciplinas que envolvem a prática da confecção. Pressupõese que essa falta de interesse esteja ligada, entre outros fatores, a problemas de usabilidade inerentes aos equipamentos (máquinas de costura) utilizados nos ateliês de costura.

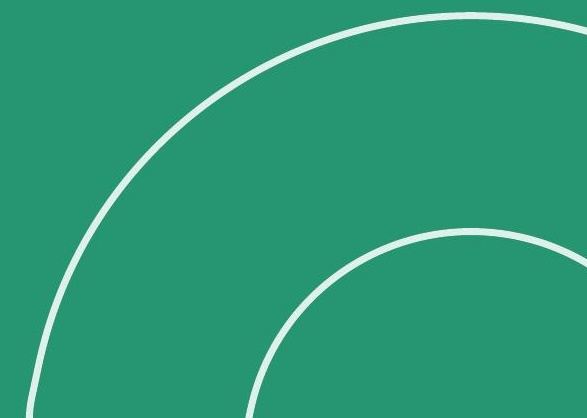


Figura 3 - Passagem da linha na máquina.

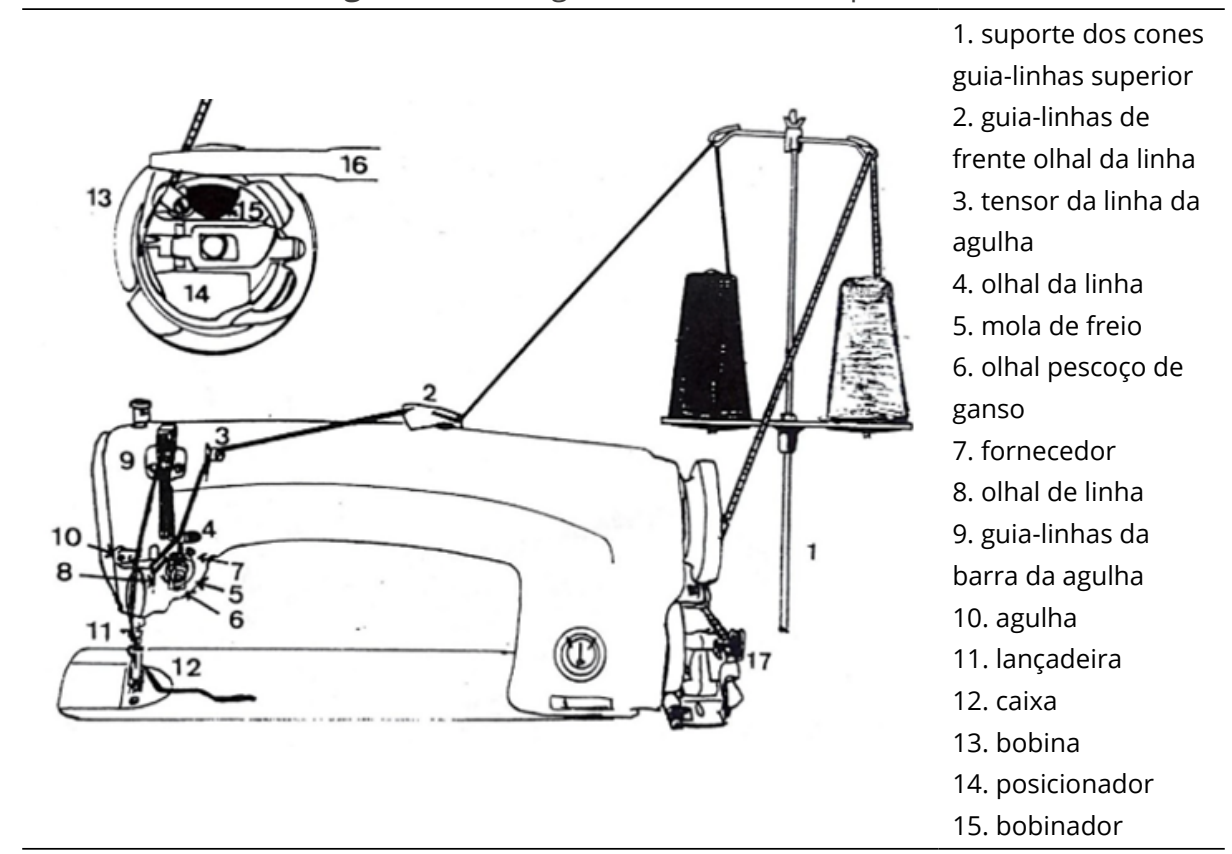

Fonte: Araújo (1996, p. 293).

Para este conjunto de tarefas foi elaborada uma tabela (Quadro 2), para cada ação realizada, visando à contabilização de erros e pontuações de dificuldades, gravidade, medição de tempo total da execução da tarefa desde o momento do primeiro contato manual da bobina até o fim da passagem da linha no buraco da agulha até o nível de sucesso da execução da tarefa.

Quadro 2 - Tabela das ações realizadas no conjunto de tarefas 1

\begin{tabular}{|c|c|c|c|c|c|}
\hline & $N^{\circ}$ Erros & Dificuldades & Gravidade & Nível de sucesso & Tempo \\
\hline \multicolumn{6}{|l|}{ Inserir bobina na caixa } \\
\hline \multicolumn{6}{|l|}{ Encaixar caixa no estojo } \\
\hline \multicolumn{6}{|l|}{$\begin{array}{l}\text { Passar a linha na parte } \\
\text { superior da máquina }\end{array}$} \\
\hline Passar linha na agulha & & & & & \\
\hline
\end{tabular}

Fonte: Os autores (2017). 
Projética, Londrina, v.11, n.1, p. 81-107, abril 2020

Para a ação de inserção de uma bobina previamente preenchida com linha na caixa, os erros foram contabilizados através da inserção no sentido incorreto (antihorário) e não passagem da linha pelo lingote da caixa. Os erros contabilizados na ação de encaixamento da caixa no estojo se deram através do não encaixe na posição correta (vertical) do dente no rebaixo do estojo. Na ação de passagem da linha na parte superior da máquina, os erros foram contabilizados a partir do somatório do número de espaços destinados à linha não preenchidos. Já os erros da ação de passagem da linha pelo buraco da agulha foram contados a partir da passagem no sentido errado (da direita para esquerda) ou com a linha torcida em torno da agulha. À gravidade foram atribuídos valores de 0 a 4, descritos de acordo com a Tabela 1.

Tabela 1 - Níveis de gravidade atribuídos às ações de manuseio da máquina de costura industrial

\begin{tabular}{ll}
\hline Nível de Gravidade & Descrição \\
\hline 0 & Não é encarado como um problema de usabilidade \\
\hline 1 & $\begin{array}{l}\text { Problema que não tem necessidade de ser corrigido, a menos que haja } \\
\text { tempo e recurso disponível. }\end{array}$ \\
\hline 2 & Pequeno problema com baixa prioridade na correção \\
\hline 3 & Problema com alta prioridade de correção \\
\hline 4 & $\begin{array}{l}\text { Catástrofe de usabilidade, ou seja, o produto só será liberado se a } \\
\text { correção for feita. }\end{array}$ \\
\hline
\end{tabular}

Fonte: Os autores (2017).

Já os níveis de sucesso atribuídos nos quadros foram anotados segundo o status de execução da tarefa, podendo ser com erros, sem erros, ou não completou a tarefa.

\subsection{Conjunto de Tarefas 2}

O segundo conjunto de atividades consistiu na operação da máquina pelos participantes. O participante foi convidado a usar a máquina industrial previamente 
preparada (com as linhas superior e inferior passadas). Para orientar o participante sobre como proceder com as costuras, além da orientação verbal do moderador, Ihes foi dado um gabarito (com três linhas retas, três linhas curvas e três linhas quebradas), conforme a figura 4. Para esse conjunto de tarefas, foi utilizada uma máquina de costura industrial com regulagem apropriada para tecidos planos e leves, bem como agulha em numeração própria para a costura desse tipo de tecido, com linhas passadas, na parte superior e inferior.

Figura 4 - Frente e verso do gabarito das linhas costuradas, usado como guia pelos participantes

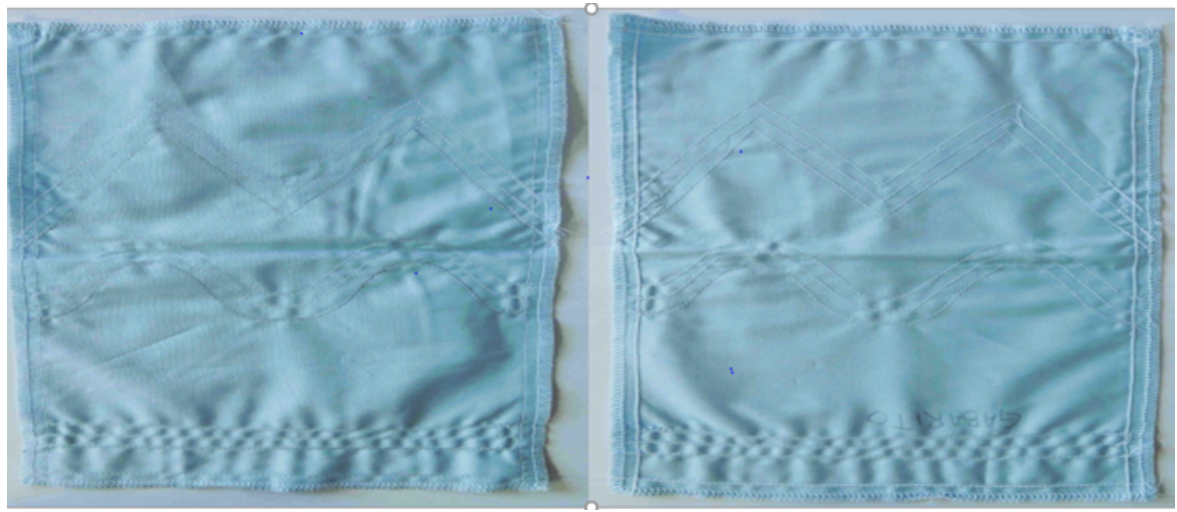

Fonte: Os autores (2017).

A tarefa consistiu em costurar dois tecidos sobrepostos, seguindo a linha traçada a lápis no gabarito, repetindo a mesma costura duas vezes para cada diferente linha, utilizando como parâmetro a linha costurada previamente. Todos os participantes foram orientados quanto à necessidade de arremate inicial e final em cada costura realizada. Esse exercício testou o domínio da máquina como um todo, com atenção à coordenação do movimento do tecido com as mãos em conjunto com a velocidade do pedal.

Para este conjunto de tarefas, foi elaborada uma tabela (Quadro 3) e para cada ação realizada foram atribuídas escalas de gravidade e níveis de sucesso, 
Projética, Londrina, v.11, n.1, p. 81-107, abril 2020

seguindo o formato no conjunto de tarefas 1 , sendo feita a medição de tempo total da execução da tarefa desde o momento do primeiro contato manual com os tecidos até o fim da última costura.

Quadro 3 - Ações realizadas no conjunto de tarefas 2

\begin{tabular}{|c|c|c|c|c|c|}
\hline & & & Gravidade & Nível de sucesso & Tempo \\
\hline \multirow{6}{*}{ Operar a máquina } & \multirow{2}{*}{ Costura reta } & Arremate inicial & & & \\
\hline & & Arremate final & & & \\
\hline & \multirow{2}{*}{$\begin{array}{l}\text { Costura } \\
\text { ondulada }\end{array}$} & Arremate inicial & & & \\
\hline & & Arremate final & & & \\
\hline & \multirow{2}{*}{$\begin{array}{l}\text { Costura } \\
\text { quebrada }\end{array}$} & Arremate inicial & & & \\
\hline & & Arremate final & & & \\
\hline
\end{tabular}

Fonte: Os autores (2017).

\subsection{Análise dos Dados}

Os dados foram analisados usando de estatística descritiva como percentuais, frequências e médias, com o auxílio do software SPSS. Foi aplicado o teste de hipótese Kruskal Wallis para comparar o desempenho de cada categoria de participantes nas duas tarefas. Aplicou-se o teste correlacional de Spearman's rho para detectar as correlações entre as variáveis ordinais de expectativa e experiência. Os autores realizaram uma análise dos testes e das respostas dos participantes às perguntas, além de suas próprias notas de observação e da avaliação visual dos gabaritos gerados por cada participante.

\section{RESULTADOS}

Os dados coletados no questionário de pretensão mostraram que 50\% dos participantes gostariam de atuar na área de Design/Estilismo, atividade que envolve criar roupas (estilismo), joias, bijuterias, calçados e bolsas (design de acessórios) ou desenhar estampas e padrões e elaborar novos tecidos para tecelagens 
(design têxtil). A área de modelagem cujo conhecimento de técnicas de costura é imprescindível teve $8,3 \%$ de respostas.

Tabela 2 - Pretensão de atuação na área de moda

\begin{tabular}{lll}
\hline Pretensão & Frequência & Porcentagem \\
\hline Coordenação & 2 & 16,7 \\
\hline Design & 6 & 50,0 \\
\hline Modelagem & 1 & 8,3 \\
\hline Negócios & 2 & 16,7 \\
\hline Produção & 1 & 8,3 \\
\hline Total & 12 & 100 \\
\hline
\end{tabular}

Fonte: Os autores (2017).

A eficiência das tarefas foi medida em tempo (s), referindo-se à velocidade ou rapidez em que o objetivo das tarefas foi completamente alcançado. A tabela 2 mostra as realizações e durações dos conjuntos de tarefas por cada participante em segundos e o tempo médio gasto para cada tarefa. Todos os participantes concluíram as tarefas.

Tabela 3 - Tempo das tarefas por cada participante

\begin{tabular}{llll}
\hline Participante & Perfil & Duração Conj. Tarefas 1 (s) & Duração Conj. Tarefas 2 (s) \\
\hline 1 & Aprendiz & 187 & 710 \\
\hline 2 & Aprendiz & 315 & 481 \\
\hline 3 & Iniciante & 227 & 652 \\
\hline 4 & Iniciante & 314 & 433 \\
\hline 5 & Leigo & 776 & 846 \\
\hline 6 & Leigo & 784 & 2115 \\
\hline 7 & Aprendiz & 357 & 739 \\
\hline 8 & Iniciante & 481 & 422 \\
\hline 9 & Leigo & 187 & 676 \\
\hline 10 & Iniciante & 125 & 559 \\
\hline 11 & Leigo & 057 & 537 \\
\hline 12 & Aprendiz & 139 & 482 \\
\hline Tempo médio & & 329 & 721 \\
\hline
\end{tabular}

Fonte: Os autores (2017). 
Projética, Londrina, v.11, n.1, p. 81-107, abril 2020

O tempo médio gasto no conjunto de tarefas 1 foi 329 s e para o conjunto de tarefas 2 foi de $721 \mathrm{~s}$. Uma análise do tempo de realização das tarefas por perfil mostra que os participantes leigos concluíram o conjunto de tarefas 1 em 451 s, os iniciantes em 286,75 s e os participantes classificados como aprendizes em 249,5 s. O participante 11 foi o mais rápido na tarefa 1. Esse voluntário foi classificado como leigo e apesar de ter completado todas as tarefas, apresentou dificuldades e erros em todas as etapas, sendo alguns de gravidade 4 . O participante que apresentou menor quantidade de erros foi número 12 , sendo um voluntário de perfil aprendiz, que completou o primeiro conjunto de tarefas em 139 s, tempo abaixo da média geral e da sua categoria. O participante mais lento foi o de número 6 (leigo), que levou $784 \mathrm{~s}$ para realizar as primeiras tarefas, tendo completado o teste com dificuldade. No segundo conjunto de tarefas o participante 8 (iniciante) foi o mais rápido. Esse voluntário completou todas as tarefas com erros, tendo utilizado a máquina de costura em alta velocidade. O participante mais lento foi o 6 que levou 2.115 segundos, ou pouco mais de 35 minutos para realizar as tarefas, tendo completado o teste com dificuldades.

Tabela 4 - Tempo das tarefas por cada participante, por categoria

\begin{tabular}{lllllll}
\hline & & \multicolumn{2}{l}{ Tempo Tarefa 1 } & \multicolumn{2}{l}{ Tempo Tarefa 2 } \\
\cline { 2 - 6 } & & Média (s) & Desvio padrão & Média (s) & Desvio padrão \\
\hline \multirow{3}{*}{ Nível Participante } & Leigo & 451 & 383 & 1053 & 725 \\
\cline { 2 - 6 } & Iniciante & 308 & 145 & 473 & 62 \\
\cline { 2 - 6 } & Aprendiz & 227 & 93 & 645 & 115 \\
\hline
\end{tabular}

Fonte: Os autores (2017).

Para identificar se existe diferença significativa entre o tempo de realização das tarefas entre os grupos foi realizado o teste de Kruskal Wallis. 
Tabela 5 - Teste Kruskal Wallis tarefa 1

\begin{tabular}{llllll}
\hline \multicolumn{7}{c}{ Test Statistics a,b } \\
\hline & Tempo Tarefa 1 & t1 bobina erro & t1 estojo erro & t1 linha erro & t1 agulha erro \\
\hline Chi-Square &, 376 & 7,333 & 4,053 & 2,571 &, 143 \\
\hline df & 2 & 2 & 2 & 2 & 2 \\
\hline Asymp. Sig. &, 828 &, 026 &, 132 &, 276 &, 931 \\
\hline \multicolumn{7}{c}{ a. Kruskal Wallis Test } \\
\hline \multicolumn{7}{c}{ b. Grouping Variable: Nível Participante }
\end{tabular}

Fonte: Os autores (2017).

Sendo que para $p<0,05$ descarta-se a hipótese nula h0, onde não há diferença de tempo entre as categorias, o erro na colocação na bobina sig=0,026, é a única variável que a hipótese nula foi descartada, ou seja, há diferença de tempo na execução da tarefa entre as categorias de participantes. Nas demais tarefas não houve diferença significativa de tempo na execução.

A eficácia foi verificada através da facilidade com a qual o usuário utilizou o sistema, e se esse se comportou conforme o esperado, sendo medida pela porcentagem de sucesso na realização da tarefa. No geral, a gravidade dos erros diminuiu com o nível de conhecimento prévio dos participantes, o que foi possível comprovar com a contagem do número de erros por tarefa, por participante, e pela análise visual dos gabaritos.

Figura 5 - Frente e verso do gabarito das linhas costuradas, por participante de nível leigo.
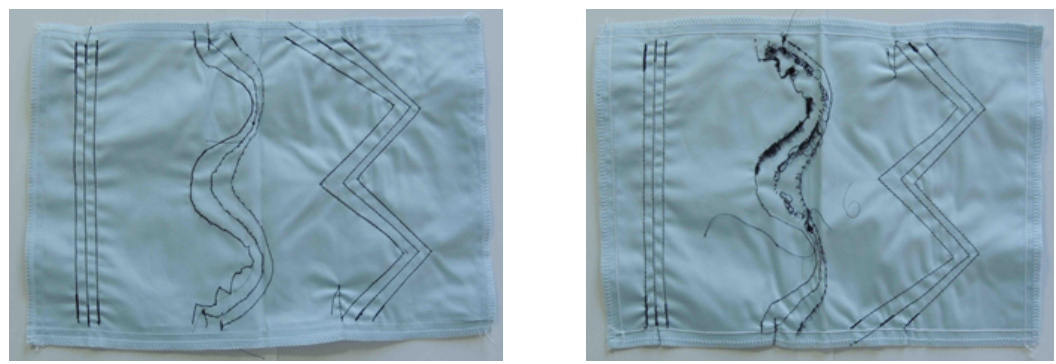

Fonte: Os autores (2017). 
Projética, Londrina, v.11, n.1, p. 81-107, abril 2020

Figura 6 - Frente e verso do gabarito das linhas costuradas, por participante de nível aprendiz
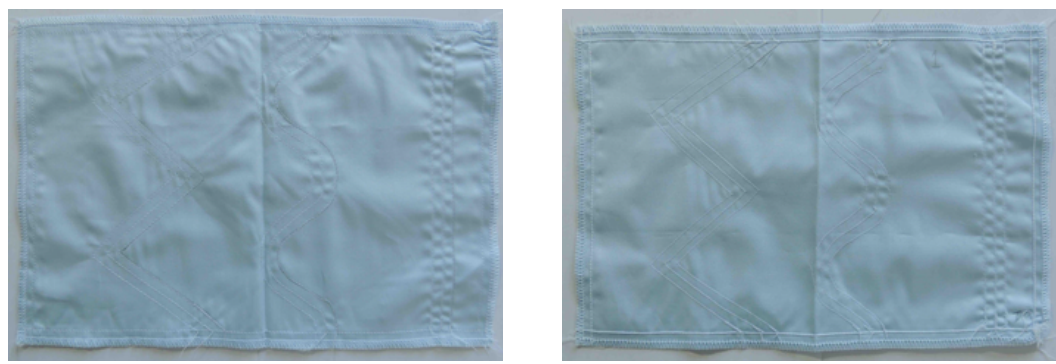

Fonte: Os autores (2017).

A satisfação relacionada às percepções, aos sentimentos e às opiniões do usuário sobre a experiência de uso das máquinas de costura foi analisada através dos questionários de auto reporte. Para o item praticidade, a medida da expectativa mostrou que mais usuários tinham a percepção de que a máquina não era prática antes do uso, o que não se confirmou com a medida da experiência, que teve uma tendência mais positiva quando indagada após o teste.

Sobre a agradabilidade do uso, 75\% dos indivíduos testados foram neutros no questionário de expectativa, porém, 50\% deles afirmaram ter tido uma experiência agradável após o uso.

Figura 7 - Expectativa sobre a praticidade da máquina de costura.

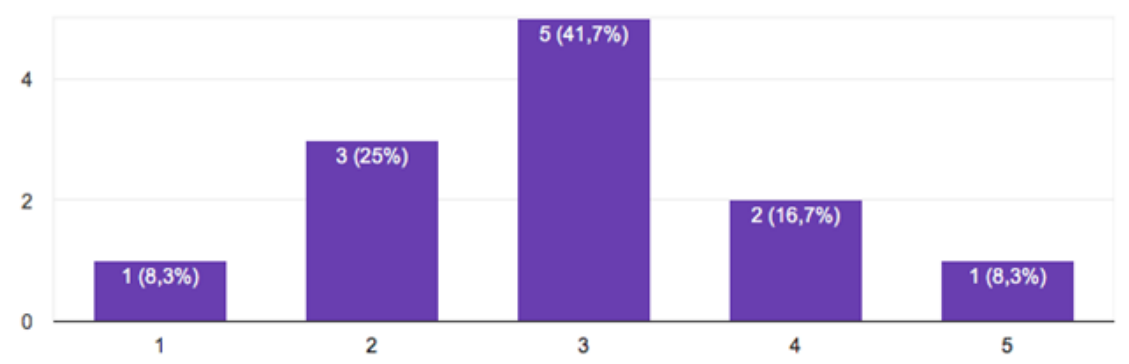

Fonte: Os autores (2017). 
Figura 8 - Experiência sobre a praticidade da máquina de costura

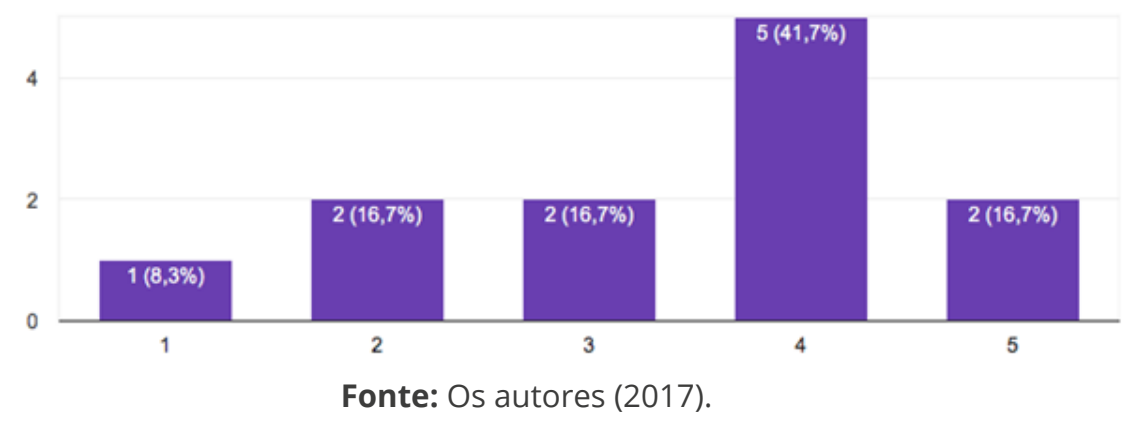

Figura 9 - Expectativa sobre a agradabilidade da máquina de costura

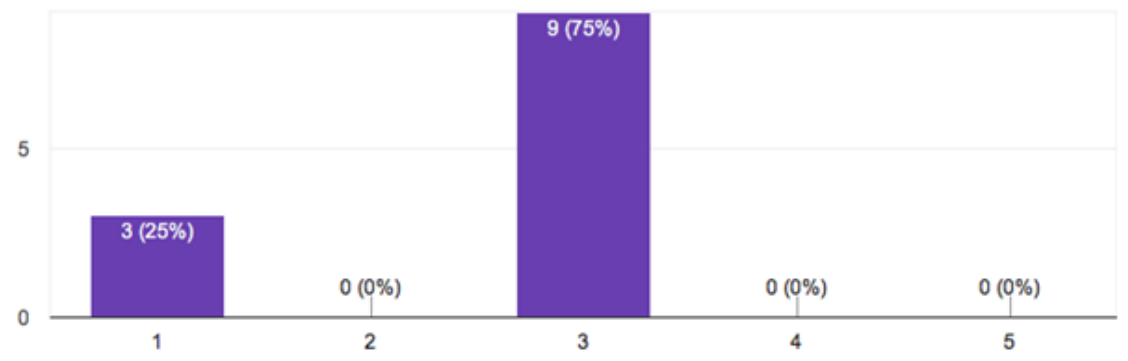

Fonte: Os autores (2017).

Figura 10 - Experiência sobre a agradabilidade da máquina de costura

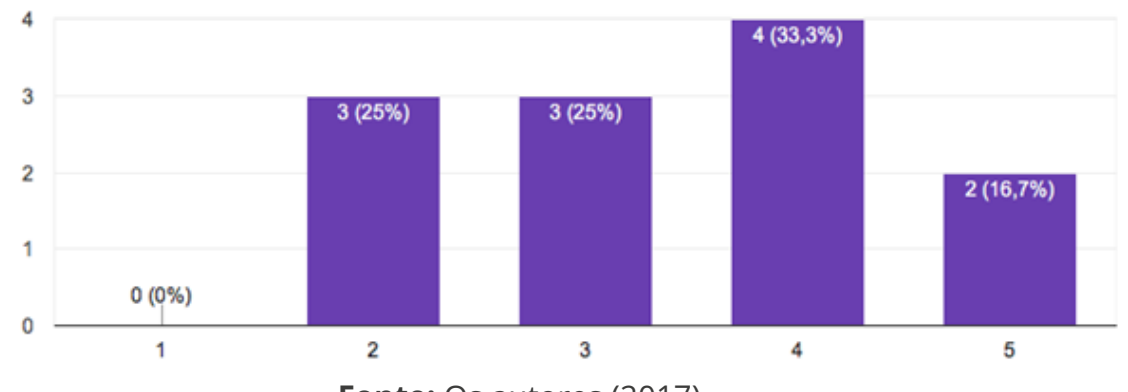

Fonte: Os autores (2017). 
Projética, Londrina, v.11, n.1, p. 81-107, abril 2020

Diferenças foram percebidas quanto às respostas por cada perfil de participante (leigo, aprendiz e iniciante), sendo que 50\% dos aprendizes (aqueles que já tinham alguma experiência prévia com as máquinas industriais) foram os que se mostraram mais negativos na expectativa, e tornando-se positivos após a experiência. 
Estudo de usabilidade das máquinas... moda

OLIVEIRA, R. P. C. et al.

Diferenças foram percebidas quanto às respostas por cada perfil de participante (leigo, aprendiz e iniciante), sendo que 50\% dos aprendizes (aqueles que já tinham alguma experiência prévia com as máquinas industriais) foram os que se mostraram mais negativos na expectativa, e tornando-se positivos após a experiência.

Tabela 6 - Teste de correlação de Spearman

\begin{tabular}{|c|c|c|c|c|c|c|c|c|c|}
\hline & & $\begin{array}{l}\text { Expec- } \\
\text { tativa } \\
\text { Com- } \\
\text { plexa }\end{array}$ & $\begin{array}{l}\text { Expec- } \\
\text { tativa } \\
\text { Intimi- } \\
\text { dadora }\end{array}$ & $\begin{array}{l}\text { Expec- } \\
\text { tativa } \\
\text { Agra- } \\
\text { dável } \\
\text { usar }\end{array}$ & $\begin{array}{l}\text { Expec- } \\
\text { tativa } \\
\text { Con- } \\
\text { fiante }\end{array}$ & $\begin{array}{l}\text { Expe- } \\
\text { riência } \\
\text { Com- } \\
\text { plexa }\end{array}$ & $\begin{array}{l}\text { Expe- } \\
\text { riência } \\
\text { Intimi- } \\
\text { dadora }\end{array}$ & $\begin{array}{l}\text { Expe- } \\
\text { riência } \\
\text { Agra- } \\
\text { dável } \\
\text { usar }\end{array}$ & $\begin{array}{l}\text { Expe- } \\
\text { riência } \\
\text { Con- } \\
\text { fiante }\end{array}$ \\
\hline \multirow{3}{*}{$\begin{array}{l}\text { Expec- } \\
\text { tativa } \\
\text { Com- } \\
\text { plexa }\end{array}$} & $\begin{array}{l}\text { Corre- } \\
\text { lation } \\
\text { Coeffi- } \\
\text { cient }\end{array}$ & 1,000 & ,575 &,$- 788^{* *}$ &,$- 648 *$ & ,639* &, 711 ** &,- 388 &,- 193 \\
\hline & $\begin{array}{l}\text { Sig. } \\
\text { (2-tai- } \\
\text { led) }\end{array}$ & & ,050 & ,002 & ,023 & ,025 & ,010 & 212 & ,548 \\
\hline & $\mathrm{N}$ & 12 & 12 & 12 & 12 & 12 & 12 & 12 & 12 \\
\hline \multirow{3}{*}{$\begin{array}{l}\text { Expec- } \\
\text { tativa } \\
\text { Intimi- } \\
\text { dadora }\end{array}$} & $\begin{array}{l}\text { Corre- } \\
\text { lation } \\
\text { Coeffi- } \\
\text { cient }\end{array}$ & ,575 & 1,000 &,- 428 &,- 126 & ,413 & ,204 & ,274 & 262 \\
\hline & $\begin{array}{l}\text { Sig. } \\
\text { (2-tai- } \\
\text { led) }\end{array}$ & ,050 & & , 165 & ,697 & 182 &, 524 & ,389 & ,410 \\
\hline & $\mathrm{N}$ & 12 & 12 & 12 & 12 & 12 & 12 & 12 & 12 \\
\hline \multirow{3}{*}{$\begin{array}{l}\text { Expec- } \\
\text { tativa } \\
\text { Agra- } \\
\text { dável } \\
\text { usar }\end{array}$} & $\begin{array}{l}\text { Corre- } \\
\text { lation } \\
\text { Coeffi- } \\
\text { cient }\end{array}$ &,$- 788 * \star$ &,- 428 & 1,000 &, $777^{\star \star}$ &,- 466 &,- 438 & 231 & 144 \\
\hline & $\begin{array}{l}\text { Sig. } \\
\text { (2-tai- } \\
\text { led) }\end{array}$ & ,002 & , 165 & & ,003 & 127 & ,155 & ,470 & 655 \\
\hline & $\mathrm{N}$ & 12 & 12 & 12 & 12 & 12 & 12 & 12 & 12 \\
\hline
\end{tabular}


Projética, Londrina, v.11, n.1, p. 81-107, abril 2020

\begin{tabular}{|c|c|c|c|c|c|c|c|c|c|}
\hline \multirow{3}{*}{$\begin{array}{l}\text { Expec- } \\
\text { tativa } \\
\text { Con- } \\
\text { fiante }\end{array}$} & $\begin{array}{l}\text { Corre- } \\
\text { lation } \\
\text { Coeffi- } \\
\text { cient }\end{array}$ &,$- 648 *$ &,- 126 &, $777 * \star$ & 1,000 &,- 260 &,- 344 & ,445 & 209 \\
\hline & $\begin{array}{l}\text { Sig. } \\
\text { (2-tai- } \\
\text { led) }\end{array}$ & ,023 & ,697 & ,003 & & ,414 & 273 & , 147 &, 515 \\
\hline & $\mathrm{N}$ & 12 & 12 & 12 & 12 & 12 & 12 & 12 & 12 \\
\hline \multirow{3}{*}{$\begin{array}{l}\text { Expe- } \\
\text { riência } \\
\text { Com- } \\
\text { plexa }\end{array}$} & $\begin{array}{l}\text { Corre- } \\
\text { lation } \\
\text { Coeffi- } \\
\text { cient }\end{array}$ & ,639* & ,413 &,- 466 &,- 260 & 1,000 & ,503 &,- 234 &,- 221 \\
\hline & $\begin{array}{l}\text { Sig. } \\
\text { (2-tai- } \\
\text { led) }\end{array}$ & ,025 & 182 & 127 & ,414 & & ,096 & ,463 & ,490 \\
\hline & $\mathrm{N}$ & 12 & 12 & 12 & 12 & 12 & 12 & 12 & 12 \\
\hline \multirow{3}{*}{$\begin{array}{l}\text { Expe- } \\
\text { riência } \\
\text { Intimi- } \\
\text { dadora }\end{array}$} & $\begin{array}{l}\text { Corre- } \\
\text { lation } \\
\text { Coeffi- } \\
\text { cient }\end{array}$ &, 711 ** & 204 &,- 438 &,- 344 & ,503 & 1,000 &,- 400 &,- 461 \\
\hline & $\begin{array}{l}\text { Sig. } \\
\text { (2-tai- } \\
\text { led) }\end{array}$ & ,010 & ,524 & ,155 & 273 & ,096 & & , 198 & ,131 \\
\hline & $\mathrm{N}$ & 12 & 12 & 12 & 12 & 12 & 12 & 12 & 12 \\
\hline \multirow{3}{*}{$\begin{array}{l}\text { Expe- } \\
\text { riência } \\
\text { Agra- } \\
\text { dável } \\
\text { usar }\end{array}$} & $\begin{array}{l}\text { Corre- } \\
\text { lation } \\
\text { Coeffi- } \\
\text { cient }\end{array}$ &,- 388 & 274 & 231 & ,445 & -234 &,- 400 & 1,000 & ,594* \\
\hline & $\begin{array}{l}\text { Sig. } \\
\text { (2-tai- } \\
\text { led) }\end{array}$ & 212 & 389 & ,470 & ,147 & ,463 & 198 & &, 042 \\
\hline & $\mathrm{N}$ & 12 & 12 & 12 & 12 & 12 & 12 & 12 & 12 \\
\hline \multirow{3}{*}{$\begin{array}{l}\text { Expe- } \\
\text { riência } \\
\text { Con- } \\
\text { fiante }\end{array}$} & $\begin{array}{l}\text { Corre- } \\
\text { lation } \\
\text { Coeffi- } \\
\text { cient }\end{array}$ &,- 193 & 262 & 144 & 209 &,- 221 &,- 461 & ,594* & 1,000 \\
\hline & $\begin{array}{l}\text { Sig. } \\
\text { (2-tai- } \\
\text { led) }\end{array}$ & ,548 & ,410 & ,655 & ,515 & ,490 & 131 & ,042 & \\
\hline & $\mathrm{N}$ & 12 & 12 & 12 & 12 & 12 & 12 & 12 & 12 \\
\hline
\end{tabular}

Fonte: Os autores (2017). 
De acordo com o resultado do teste de correlação de Sperman (tabela 6), o item Expectativa (antes do uso) com relação à Complexidade da Máquina apresentou correlação positiva e significante com o mesmo item na Experiência (depois do uso), confirmando o fato desta ser complexa $(R=0,639)$. O mesmo aconteceu com o sentimento de intimidação $(R=0,711)$. Ou seja, as pessoas que esperavam que o uso da máquina fosse complexo relataram uma experiência intimidadora.

Questões relacionadas ao sentimento após o uso foram mensuradas através de questionário de diferencial semântico, numa escala de 5 pontos. Quanto à 'satisfação', nota-se que os leigos se mostraram mais satisfeitos de forma absoluta, mas de modo geral a experiência traz um grau de satisfação maior do que de insatisfação para todos os níveis.

Tabela 7 - Nível de satisfação nas tarefas, por nível de participante

\begin{tabular}{|c|c|c|c|c|c|c|}
\hline & & Sentim & ento - & satisfação & & \\
\hline & Satisfeito & Pouco satisfeito & Neutro & Pouco insatisfeito & insatisfeito & Total \\
\hline Leigo & 2 & 0 & 0 & 1 & 1 & 4 \\
\hline Iniciante & 0 & 2 & 1 & 1 & 0 & 4 \\
\hline Aprendiz & 1 & 2 & 0 & 1 & 0 & 4 \\
\hline Total & 3 & 4 & 1 & 3 & 1 & 12 \\
\hline
\end{tabular}

Fonte: Os autores (2017).

O item 'realização' foi também avaliado por este método. Na tabela se percebe uma inclinação mais positiva para a realização, mas alguns indivíduos leigos e iniciantes com uma tendência maior a frustração.

Para o quesito 'segurança', a tabela de frequência mostra que nenhum indivíduo se sentiu totalmente seguro, e entre os leigos e iniciantes, 75\% manifestaram um pouco de insegurança no manuseio da máquina de costura. 
Projética, Londrina, v.11, n.1, p. 81-107, abril 2020

Tabela 8 - Nível de realização nas tarefas, por nível de participante

\begin{tabular}{|c|c|c|c|c|c|c|}
\hline & \multicolumn{3}{|c|}{ Sentimento - } & \multicolumn{2}{|l|}{ realização } & \multirow[b]{2}{*}{ Total } \\
\hline & Realizado & Pouco realizado & Neutro & Pouco frustrado & Frustrado & \\
\hline Leigo & 2 & 0 & 0 & 1 & 1 & 4 \\
\hline Iniciante & 1 & 0 & 2 & 1 & 0 & 4 \\
\hline Aprendiz & 1 & 1 & 1 & 1 & 0 & 4 \\
\hline Total & 4 & 1 & 3 & 3 & 1 & 12 \\
\hline
\end{tabular}

Fonte: Os autores (2017).

Tabela 9 - Nível de segurança nas tarefas, por nível de participante

\begin{tabular}{llllll}
\hline \multicolumn{7}{c}{ Sentimento } & segurança & \\
\hline & Pouco seguro & Neutro & Pouco inseguro & Inseguro & Total \\
\hline Leigo & 1 & 0 & 3 & 0 & 4 \\
\hline Iniciante & 1 & 0 & 3 & 0 & 4 \\
\hline Aprendiz & 2 & 1 & 0 & 1 & 4 \\
\hline Total & 4 & 1 & 6 & 1 & 12 \\
\hline
\end{tabular}

Fonte: Os autores (2017).

Por fim, questionou-se se os indivíduos se sentiram orgulhosos ou decepcionados em relação à experiência, resultando nos seguintes dados: os indivíduos com menos experiência demonstraram um sentimento de orgulho maior que os indivíduos aprendizes.

Tabela 10 - Nível de orgulho nas tarefas, por nível de participante

\begin{tabular}{|c|c|c|c|c|c|c|}
\hline & & Sentin & ento - & Orgulho & & \\
\hline & Orgulhoso & Pouco Orgulhoso & Neutro & $\begin{array}{l}\text { Pouco } \\
\text { decepcionado }\end{array}$ & Decepcionado & Total \\
\hline Leigo & 2 & 0 & 0 & 1 & 1 & 4 \\
\hline Iniciante & 0 & 2 & 1 & 1 & 0 & 4 \\
\hline Aprendiz & 1 & 2 & 0 & 1 & 0 & 4 \\
\hline Total & 3 & 4 & 1 & 3 & 1 & 12 \\
\hline
\end{tabular}

Fonte: Os autores (2017). 
Os resultados mais negativos foram atribuídos aos indivíduos leigos, pois em todos os quatro itens eles figuram ao menos uma vez na coluna da direita, que representa os aspectos mais negativos da experiência.

No final dos testes com as máquinas foi realizado um debriefing para captar algumas percepções mais subjetivas dos participantes a respeito do uso das máquinas industriais.

De modo geral, os participantes relataram que a experiência com o uso das máquinas foi melhor do que era esperada antes dos testes. Alguns pontos se repetiram nos comentários dos participantes: a alta sensibilidade do pedal da máquina foi considerado um ponto negativo, pois dificulta o controle da costura. Por outro lado, concordou-se que a máquina industrial oferece uma maior eficiência na costura, tanto pelos atalhos que ela oferece (ex: corte de linha automático) como pela precisão da costura e dos pontos, deste modo, vários participantes comentaram sua preferência pela máquina industrial ao invés da doméstica.

\section{CONCLUSÕES}

Os dados mostram que a maioria dos alunos pretende atuar na área de criação (Design/Estilismo), podendo esta ser uma justificativa para o fato que muitos profissionais não têm interesse em aprimorar os conhecimentos técnicos de costura em nível de desempenho industrial.

O fato de nenhum indivíduo ter se mostrado totalmente seguro na experiência leva a concluir que possivelmente uma série de fatores subjetivos não analisados neste estudo possa estar influenciando negativamente à percepção da amostra analisada. A falta de contato com a máquina e a concepção de facilidade de 
Projética, Londrina, v.11, n.1, p. 81-107, abril 2020

uso, bem como a não disponibilidade de manual anexo ou próximo ao maquinário podem também estar contribuindo para esta percepção.

De uma maneira geral, o fator tempo, analisado no conjunto de tarefas 1 e 2, não se mostrou decisivo nem influenciador do interesse e desempenho dos participantes. Outros fatores subjetivos como a percepção de agradabilidade, tomadas antes e depois da execução do conjunto de tarefas 1 e 2, mostraramse distintas, uma vez que o experimento permitiu ao participante desmistificar possíveis impressões e noções previamente estabelecidas.

Entende-se que este estudo contribui no sentido de estabelecer requisito e fatores - de natureza objetiva e subjetiva - a serem considerados em um teste de usabilidade de produtos, principalmente no que concerne a produtos utilizados no dia a dia pela indústria.

Como sugestão para trabalhos futuros, indica-se a aplicação do experimento em uma amostra de maior número, a fim de que se possam explorar quantitativamente e de forma estatística outras correlações características deste público estudado.

Em alguns casos, a funcionalidade e o desempenho não são suficientes para satisfazer o usuário, que opta por outro sistema com interface atrativa. Além de inovação e qualidade, usuários optam cada vez mais por produtos na qual tenha uma maior identificação, interação entre o produto e usuário.

\section{AGRADECIMENTOS}

Agradecemos à CAPES, à UDESC e ao técnico de laboratório Trajano da Silveira Júnior, por sua colaboração durante o uso do ateliê do curso de Moda da UDESC. 


\section{REFERÊNCIAS}

1. ARAÚjo, Mário. Tecnologia do vestuário. Lisboa: Fundação Calouste Gulbe, 1996.

2. ASSOCIAÇÃO BRASILEIRA DE NORMAS TÉCNICAS. NBR ISO 9241-11: requisitos ergonômicos para o trabalho com dispositivos de interação visual. Rio de Janeiro: ABNT, 1998.

3. FALCÃO, Christianne.; SOARES, Marcelo. Usabilidade de produtos de consumo: uma análise dos conceitos, métodos e aplicações. Estudos em Design, Rio de Janeiro, v. 21, n. 2, p. 1-26, 2013.

4. HIX, Deborah; HARTSON, H Rex. Developing user interfaces: ensuring usability through product and process. New York: John Wiley and Sons, 1993.

5. MANUAL de instruções em português da máquina de costura. São Paulo: Janome do Brasil Comércio de Máquinas 2008.

6. MORAES, Anamaria; MONT'ALVÃO, Cláudia R. Ergonomia: conceitos e aplicações. Rio de Janeiro: iUsEr, 2003.

7. RUBIN, Jeffrey; CHISNELL, Dana. Handbook of usability testing: how to plan, design, and conduct effective tests. Indianapolis: Wiley, 2008.

8. TULLIS, Thomas; ALBERT, William. Measuring the user experience: collecting, analyzing, and presenting usability metrics. Burlington: Morgan Kaufmann Publishers, 2008.

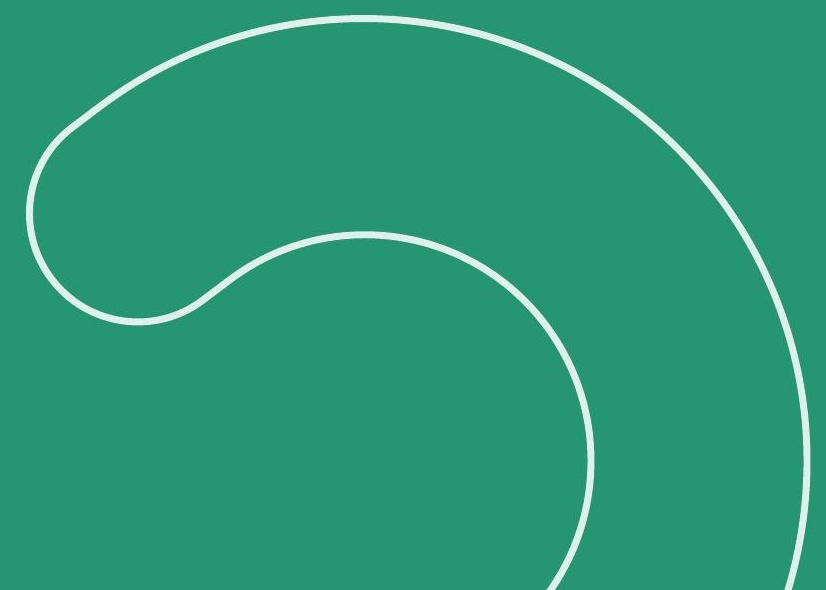

